\title{
Histone H3 Lysine 79
}

National Cancer Institute

\section{Source}

National Cancer Institute. Histone H3 Lysine 79. NCI Thesaurus. Code C156388.

The lysine residue found at amino acid position 79 in the histone $\mathrm{H} 3$ protein. Methylation

of this residue by DOT $1 \mathrm{~L}$ protein disrupts telomeric silencing and may be a marker for cellular transformation and disease prog ression in patients with leukemia. 